\title{
Pond characteristics as determinants of species diversity and community composition in desert bats
}

\author{
O. Razgour ${ }^{1 *}$, C. Korine ${ }^{1,2} \&$ D. Saltz ${ }^{1}$ \\ 1 Mitrani Department of Desert Ecology, Jacob Blaustein Institutes for Desert Research, Ben-Gurion University of the Negev, Midreshet \\ Ben-Gurion, Israel \\ 2 Ramon Science Centre, Mitzpe Ramon, Israel
}

\section{Keywords}

arid environments; Chiroptera; water bodies; microhabitat; acoustic monitoring; drinking frequency.

\section{Correspondence}

Carmi Korine, Jacob Blaustein Institutes for Desert Research, 84990 Midreshet Ben-Gurion, Israel. Tel: + 97286596773 ; Fax: + 97286596772

Email: ckorine@bgu.ac.il

*Current address: School of Biological Sciences, University of Bristol, Woodland Road., Bristol BS8 1UG, UK

Received 17 December 2009; accepted 31 March 2010

doi:10.1111/j.1469-1795.2010.00371.x

\begin{abstract}
Although water availability is known to affect landscape-scale patterns of wildlife diversity and distribution in arid environments, little is known about the microhabitat characteristics that shape the local-scale distribution of desert bats. We examined the relative importance of pond microhabitat characteristics for the conservation of bats, and hypothesized that in arid environments, patterns of bat diversity and community composition relate to the size of the pond and its hydroperiod (the number of months a pond holds water), a term we use to distinguish between permanent, semi-permanent and temporary ponds. We combined acoustic monitoring with video recording and an experimental approach to study bat activity over natural ponds in the Negev Desert, Israel. We found that both within and between ponds bat species richness and activity significantly increased with pond size. An experimental reduction of pond size led to a significant reduction in bat species richness and activity and affected the bat community composition. In contrast to pond size, pond hydroperiod did not affect bat diversity, as temporary ponds had equivalent levels of bat species richness and activity to permanent ponds. However, hydroperiod did couple with pond size to affect the bat community composition, whereby non-desert bat species that have a higher frequency of drinking were associated with larger and more permanent ponds. Our results highlight the importance of larger temporary ponds (ponds over $15 \mathrm{~m}$ in length and $0.5 \mathrm{~m}$ in depth) for the conservation of biodiversity in arid environments.
\end{abstract}

\section{Introduction}

Bats are important components of the mammalian fauna in semi-arid and arid environments (inclusively referred to here as arid environments), comprising one of the most diverse and successful groups of desert mammals (Carpenter, 1969). Although flight affords bats a relatively high mobility and dispersal ability, the local-scale distribution of bats can be shaped by microhabitat characteristics that affect the amount of insect prey available and determine the quality of the foraging habitat (Biscardi et al., 2007; McCain, 2007). In arid environments, on the habitat scale, bat activity concentrates near bodies of water (Korine \& Pinshow, 2004; Rebelo \& Carlos Brito, 2006). However, little is known about microhabitat characteristics that shape the local-scale distribution of desert-dwelling bats.

Differences in the use of foraging microhabitat among bats could be related to differences in their foraging mode, physiological requirements, echolocation and manoeuvrability (Aldridge \& Rautenbach, 1987). Bats are known to use bodies of open water for drinking and/or foraging (Tuttle, Chambers \& Theimer, 2006), yet the importance of free water for desert bats is still unclear (Kurta, 2001). When relative humidity is low, bats may lose up to $30 \%$ of their body mass per day by evaporation (Webb, Speakman \& Racey, 1995). However, some desert insectivorous bats have efficient water conservation mechanisms, such as reduced evaporative water loss rates (Marom et al., 2006) and high urine concentrating abilities (Carpenter, 1969). Hence, some desert bat species appear to be physiologically less dependent on free water, and are therefore expected to have lower frequencies of drinking than non-desert species found in arid environments.

Because bats drink in flight, they require an unobstructed 'swoop zone' to manoeuvre. Consequently, bats that use bodies of water for drinking will be restricted by the minimum pond size they can use. Moreover, flight characteristics of the bat determine the minimum pond size that it can use, whereby small and more manoeuvrable bats are able to drink from smaller ponds (Tuttle et al., 2006). Therefore, microhabitat characteristics like size and accessibility of the water source may affect the local-scale community composition of bats.

\begin{tabular}{|ll|l|}
\hline Dispatch: 17.4.10 & Journal: ACV & CE: Supriya \\
\hline Author Received: & No. of pages: 9 & Op: Aswani/Jay \\
\hline
\end{tabular}


We studied patterns of bat species richness, activity and community composition over permanent and temporary ponds to determine the effect of microhabitat characteristics on the local-scale distribution of bats in arid environments. Temporary ponds have largely been ignored by policy makers due to their relatively small size and apparent lack of benefit for human use (Schwartz \& Jenkins, 2000). However, during spring and early summer, temporary ponds may serve as important foraging grounds for aquatic and terrestrial species. Studies from around the world, and in particular those from arid environments, highlight the importance of temporary ponds for rare and endemic aquatic species (Nicolet et al., 2004). Hydroperiod (defined here as the number of months the pond holds water) is recognized as a major abiotic gradient that structures pond communities (Meester et al., 2005) and affects species richness and food web structure in temporary ponds (Schneider, 1997).

We predicted that: (1) bat species richness and activity levels will increase with pond size because larger ponds can support both drinking and foraging bat species of all levels of manoeuvrability; (2) because water is a scarce resource in arid environments, pond size will have a stronger effect on bat diversity than pond hydroperiod, and therefore temporary ponds, when present, will have equivalent levels of bat species richness and activity to permanent ponds of a similar size; (3) bats with a higher frequency of drinking will be associated with larger and more permanent ponds than bats with a low frequency of drinking, because these ponds are likely to be a more reliable source of free water.

\section{Methods}

\section{Study area}

The study was conducted in the Central Negev Desert, Israel. The annual precipitation in the area ranges between 35.65 and $175.33 \mathrm{~mm}$, with high inter- and intra-annual variability (Meteorology Unit BIDR, 2008). We compared bat assemblages over 10 natural permanent and temporary ponds of different sizes (Table 1) within the Matsok HaZinim Nature Reserve $\left(30^{\circ} 51^{\prime} \mathrm{N}, 34^{\circ} 53^{\prime} \mathrm{E}\right)$. During spring, after heavy floods, there are c. 15 medium-large ponds (pond length $>10 \mathrm{~m}$ ) along these valleys. The size of all ponds varies throughout spring and summer, with temporary ponds progressively shrinking until completely drying out, leaving only five permanent ponds by midsummer. Vegetation is sparse and concentrates along dry river valleys and permanent springs. We selected ponds surrounded by vegetation, where Typha sp., Tamarix sp. and Juncus sp. were the principal plant species.

\section{Field sampling}

We recorded bat activity over each pond for one whole night every month, between March and November 2007, and over temporary ponds until the ponds dried out. We used bat detectors (AnaBat II, Titley Electronics, Australia) to record bat activity over the ponds. We placed the detector up to $2 \mathrm{~m}$ away from the pond edge, pointing upwards at a $45^{\circ}$ angle. The typical detection range of the detector for aerial foraging bats is $>20 \mathrm{~m}$ (Collins \& Jones, 2009), covering the length of most ponds (Table 1). We analysed the output of the detector using the ANALOOK software (version 3.3f). Because calls of bats found in the area do not overlap (Benda et al., 2008; Table 2), we were able to distinguish individual calls to the species level.

Bat activity is defined as the number of bat passes per hour of recording at each pond, whereby a pass is a sequence of bat calls (Fenton, 1970). Each AnaBat recording file contains at least one bat pass. Species richness was determined based on the number of bat species recorded over each pond, during the entire night.

Each sampling night, we measured the maximum length, width and depth of the ponds, and multiplied these variables to calculate an index of the maximum pond volume. Pond depth was measured at the centre of each pond. We determined pond hydroperiod based on the number of months the pond held water, and divided ponds into permanent, semi-permanent (held water until mid summer) and temporary ponds (held water until the end of spring). We estimated the per cent of woody or herbaceous vegetation cover immediately adjacent to each pond following Korine \& Pinshow (2004). We measured the average and minimum night ambient temperature $\left(T_{\mathrm{a}}\right)$ using iButtons ${ }^{\circledR}$, tied to the vegetation near each pond at $c .0 .5 \mathrm{~m}$ above the ground. We did not record bat activity on rainy or especially

Table 1 The location (Israel Nation Grid coordinate system), maximum size, size category and hydroperiod category of the 10 study ponds

\begin{tabular}{llccll}
\hline & GPS coordinates & Length $(\mathrm{m})$ & Volume $\left(\mathrm{m}^{3}\right)$ & Size & Hydroperiod \\
\hline Pond 1 & $12.7256 ; 02.6130$ & 25.1 & 302.4 & Large & Permanent \\
Pond 2 & $12.7566 ; 02.6574$ & 61.5 & 637.7 & Large & Permanent \\
Pond 3 & $12.7923 ; 02.6997$ & 9.4 & 9.1 & Small & Temporary \\
Pond 4 & $12.8757 ; 02.8139$ & 30 & 45.9 & Medium & Semi-permanent \\
Pond 5 & $12.9263 ; 02.8221$ & 15.1 & 16.9 & Small & Semi-permanent \\
Pond 6 & $13.0901 ; 02.8134$ & 21.4 & 70.2 & Medium & Temporary \\
Pond 7 & $13.1677 ; 02.6207$ & 6.2 & 9.3 & Small & Temporary \\
Pond 8 & $13.1900 ; 02.5594$ & 33.5 & 201 & Large & Temporary \\
Pond 9 & $13.1946 ; 02.5292$ & 8.9 & 19.4 & Medium & Semi-permanent \\
Pond 10 & $13.2035 ; 02.4948$ & 15.8 & Large & Permanent \\
\hline
\end{tabular}


windy nights, and on full moon nights, in case these factors affect bat activity levels.

\section{Analysing drinking frequencies}

$\equiv$ oustic monitoring was combined with video recording to $\overline{\bar{V}}_{\mathrm{d} 1 \mathrm{stinguish}}$ between species that use ponds for drinking and those that use ponds primarily for foraging. We filmed bat activity using night filming mode (SONY DCR-PC110E Pigital Handycam, Japan) and a $12 \mathrm{~V}$ infrared flood lamp (30-40 m range, 140 LEDs, Model IR-8010). Filming took place at two medium-large ponds for six nights in total during the summer of 2007 and the spring of 2008, for an average of $4 \mathrm{~h}$ each night. We calibrated the time of the video recordings with the detector placed under the camera stand, to identify the filmed bats based on their echolocation calls. Because bats swooped down to drink, we were able to determine whether the filmed bat was drinking or foraging. Frequency of drinking was determined for each species according to the ratio of AnaBat files with filmed drinking events to the overall number of AnaBat files in which the calls of the species were recorded during the filming period. We divided the bats into species with a high (filmed drinking in $>75 \%$ of the AnaBat files), medium (33-66\%), low $(<20 \%)$ and very low frequency of drinking $(<3 \%)$.

\section{Experimental manipulation}

We carried out an experiment to test the effect of pond size on bat species richness, activity and community composition. We reduced the length of three large permanent ponds by covering more than half of the pond length (leaving a space under $8 \mathrm{~m}$ in length uncovered) with a plastic sheet that prevented bats from accessing that part of the pond. Manipulations lasted for two to three consecutive nights, to provide time to $\theta_{\triangle}$ bats to respond to the manipulation. We repeated the experiment in June 2007, September 2007 and April 2008. We recorded changes in bat species richness and activity following the covering of the ponds. As a control, we recorded bat activity over the same ponds without manipulations before commencing each set of experiments. To account for daily fluctuations in bat activity, we recorded bat activity over a fourth pond during each sampling night, and measured $T_{\mathrm{a}}$ as described above.

\section{Data analysis}

To determine which habitat characteristics affect bat species richness and activity, we performed backward multiple regressions with the following habitat variables: pond length, pond volume, the number of months the pond held water, distance of the pond to nearest permanent water source and per cent of vegetation cover. Inter-correlated predictor variables were excluded from the multiple regression analysis. To avoid pseudo-replications due to repeated measures of ponds, we only included in the statistical analysis one measure of each pond, when it was at its maximum size $(n=10)$. To test the effect of natural seasonal changes in pond size, we compared bat species richness and activity over the same ponds when they were at their minimum and maximum size using Wilcoxon's matched pairs test. We used Moran's I plots in ArcGIS (version 9.2, ESRI) to test whether spatial autocorrelation, whereby ponds of similar sizes are clustered together, may affect the analysis.

To test the effect of pond hydroperiod, we compared bat species richness and activity over three permanent and three temporary ponds, with repeated measures of each between March and May. To tease apart the effect of pond hydroperiod from pond size, we only included medium to large temporary ponds in the analysis (maximum length $15-35 \mathrm{~m}$ ). To study the effect of the desiccation of temporary ponds on bat assemblages over the remaining ponds, bat species richness and activity over the six semi-permanent and temporary ponds was compared between May, when temporary ponds were present, and June, once temporary ponds dried out.

We tested for associations between bats with different frequencies of drinking and pond size and hydroperiod categories using the $\chi^{2}$-test and we divided ponds into three size categories based on their length (small $<10 \mathrm{~m}$, medium: 10-20 m, large: 21-65 m). Statistical analyses were performed with STATISTICA (version 7 StatSoft Inc.) and sPSS 

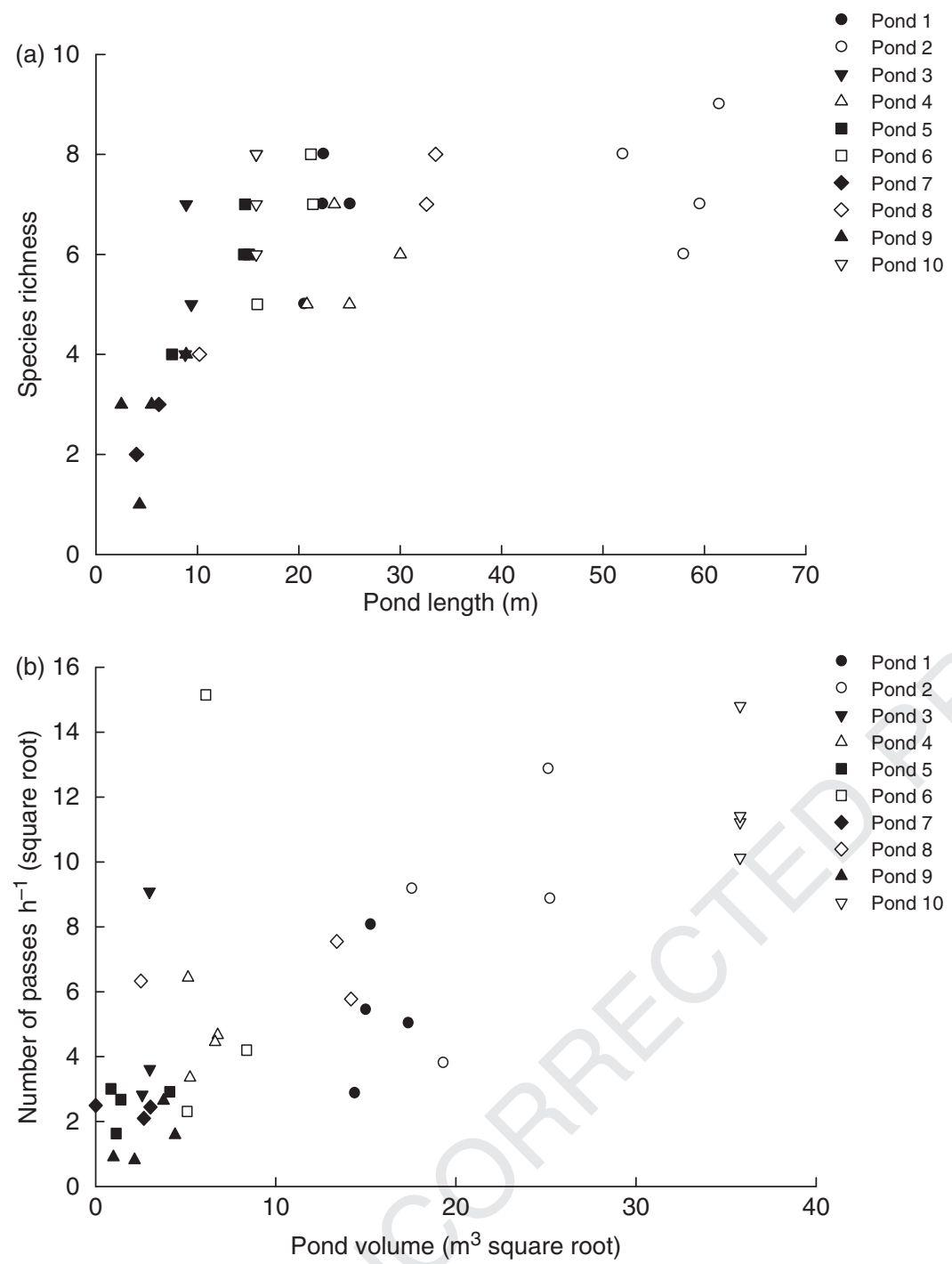

Figure 1 (a) The increase in bat species richness with an increase in pond length, and (b) the increase in bat activity with an increase in pond volume (square root transformed) between March and June 2007, when temporary ponds were present in the study area. Each pond was repeatedly measured once a month until drying out.

(version 11.5). When data did not meet the assumptions of normality or homogeneity of variance, either the data were square root transformed or we used non-parametric tests.

\section{Results}

Overall, we recorded 10 out of the 12 bat species known to be found in the area. Pipistrellus kuhlii was by far the most common species. It was recorded over all ponds at all sampling nights and had the highest proportional activity over the majority of ponds. Other common species were Tadarida teniotis and two species that were only present in spring and autumn, Hypsugo bodenheimeri and Pipistrellus rueppelli. The rarest species were Rhinolophus hipposideros and Rhinolophus clivosus (Table 2).

\section{Effect of pond size}

When all data were included, we observed a logarithmic increase in bat species richness with an increase in pond length (Fig. 1a), and a linear increase in bat activity with an increase in pond volume (Fig. 1b). However, statistical analysis was only carried out on one measure of each pond, at maximum size, to avoid pseudo replications.

The number of months the pond held water (hydroperiod) was omitted from the multiple regression analyses due to strong correlations between hydroperiod and pond volume $\left(R^{2}=0.72, F_{1,8}=20.8, P=0.002\right)$. Contrary to expectations, pond length and volume were not correlated $\left(R^{2}=0.23\right.$, $P=0.16)$. None of the remaining microhabitat characteristics (pond or volume, distance to the nearest permanent pond and per cent of vegetation cover) were inter-correlated, and were included in the multiple regression analyses.

Because species richness is represented by integer values, it was fitted into a generalized linear multiple regression model with Poisson's distribution and a logarithmic fit. Out of the four microhabitat characteristics, only pond length had a significant effect, whereby bat species richness increased with pond length (Wald statistics $=6.37$, d.f. $=1$, 

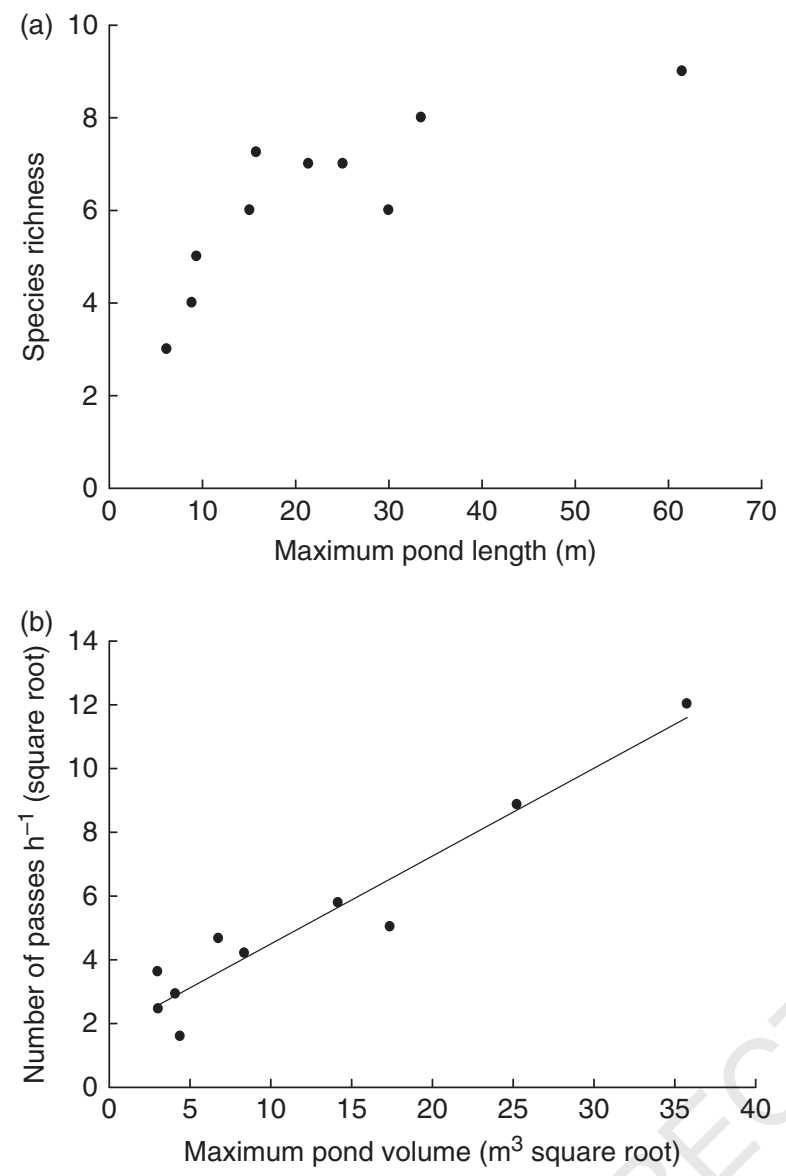

Figure 2 (a) The increase in bat species richness with an increase in pond length, and (b) the increase in bat activity with an increase in pond volume (square root transformed) over the 10 ponds when at their maximum length and volume, respectively.

$n=10, P=0.012 ; \chi^{2}=4.88, P=0.027$; Fig. 2 a). Bat activity, on the other hand, was normally distributed once square root transformed (Shapiro-Wilk test: $W=0.88, P=0.14$ ), and was therefore analysed using a generalized linear multiple regression model. Bat activity was strongly positively correlated with pond volume $\left(R^{2}=0.93, F_{1,9}=100.98\right.$, $P<0.0001, y=1.74+0.27 x$; Fig. 2 b), but was not affected by the remaining parameters.

A pairwise comparison of species richness over the same pond, at the minimum and the maximum size, showed that bat species richness was significantly higher when ponds were longer (Wilcoxon's matched pairs: $Z_{9}=2.67$, $P=0.008)$. Similarly, bat activity over the same pond was significantly higher when the pond was at its largest size (Wilcoxon's matched pairs: $Z_{9}=2.2, P=0.028$ ). Hence, both between and within ponds, bat species richness and activity increased with pond size. This pattern cannot be attributed to spatial autocorrelation, as ponds were neither spatially clustered nor dispersed based on size (Moran's $I$ index $=-0.22, Z$ score $=-0.87$ ).

Experimental manipulation of pond length caused a significant reduction in bat species richness from an average

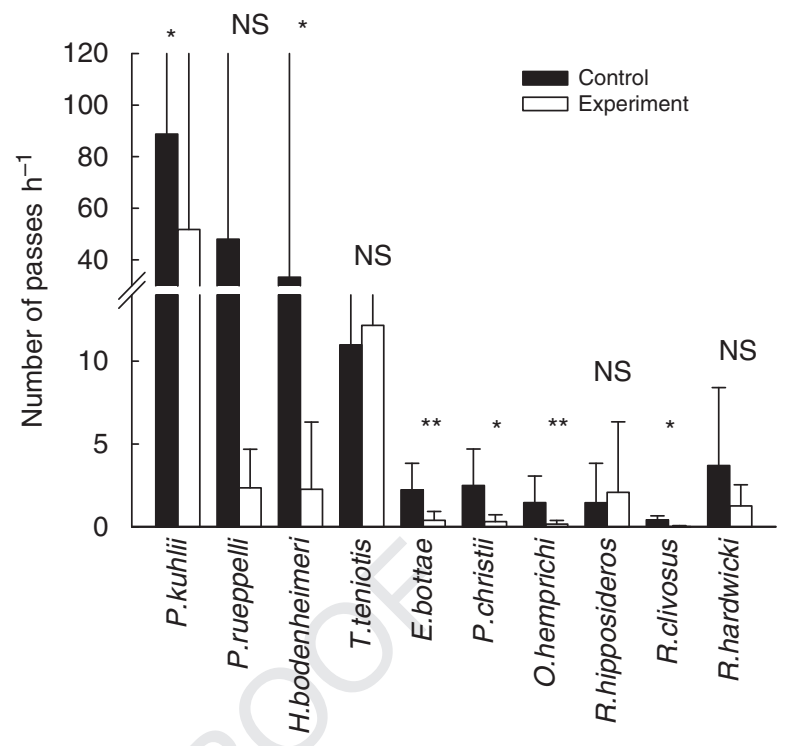

Figure 3 Average activity and SD of the 10 bat species under the control and the experimental manipulation of pond size. NS indicates no significant differences; *significant differences at $P<0.05$; and ** significant differences at $P<0.01$, based on Wilcoxon's matched pairs tests.

of $7.9 \pm 1$ to $5.5 \pm 1$ bat species per pond (Wilcoxon's matched pairs: $\left.Z_{9}=2.66, P=0.007\right)$. Similarly, bat activity levels were significantly reduced from an average of $133.8 \pm 147$ to $69.1 \pm 81$ passes per hour (repeated-measures ANOVA: $\left.F_{1,8}=6.26, P=0.037\right)$. Manipulation of pond length also led to a significant reduction in the activity of six out of the 10 bat species present in the study area (Wilcoxon's tests, $P<0.05$ ). The greatest proportional reduction ( $>90 \%$ ) was in the activity of $H$. bodenheimeri and $R$. clivosus. In contrast, the activity of $T$. teniotis increased by $2.1 \%$; however, this increase was not statistically significant (Fig. 3).

\section{Effect of hydroperiod}

Bat activity was not affected by pond hydroperiod (repeated-measures ANOVA: $P=0.4$ ) and did not differ among the three spring months (repeated-measures ANOVA: $P=0.1)$. Because bat species richness was not normally distributed, the effect of pond hydroperiod was tested separately for each month using non-parametric tests (Mann-Whitney $U$-test), and a Bonferroni correction was applied. During all three months, bat species richness did not differ between permanent and temporary ponds (Mann-Whitney: March $-P=0.27$, April $-P=0.83$, May $P=0.13)$.

An increase in bat species richness (Wilcoxon's matched pairs: $Z_{6}=2.20, P=0.03$ ) and activity ( $t$-test dependent samples: $\left.t_{5}=-3.29, P=0.02\right)$ over the remaining semipermanent and permanent ponds was observed when the temporary ponds dried out in June. 


\section{Effect of pond characteristics on bat drinking activity}

Frequency of drinking events varied between the bat species (Table 2). The proportional activity of bats with different frequencies of drinking differed among the three pond size $\left(\chi^{2}=92.5\right.$, d.f. $=6, P<0.01$, Fig. $\left.4 \mathrm{a}\right)$ and pond hydroperiod categories $\left(\chi^{2}=51.8\right.$, d.f. $=6, P<0.01$, Fig. 4 b). Tadarida teniotis, the species with a high frequency of drinking $(81 \%)$, was associated with large (standardized residuals: $\chi=3.3$ ) and permanent $(\chi=4.3)$ ponds, but avoided temporary ponds $(\chi=-4.4)$. This finding is confirmed by the strong positive correlation between the activity of $T$. teniotis and pond volume $\left(R^{2}=0.83, F_{1,9}=40.5, P<0.0001\right)$. Pipistrellus kuhlii, the species with a medium frequency of drinking $(41 \%)$, was associated with small $(\chi=5.4)$ and semi-permanent ponds $(\chi=1.8)$, while species with a low frequency of drinking were associated with medium-sized ponds $(\chi=3.7)$, but were not affected by pond hydroperiod.
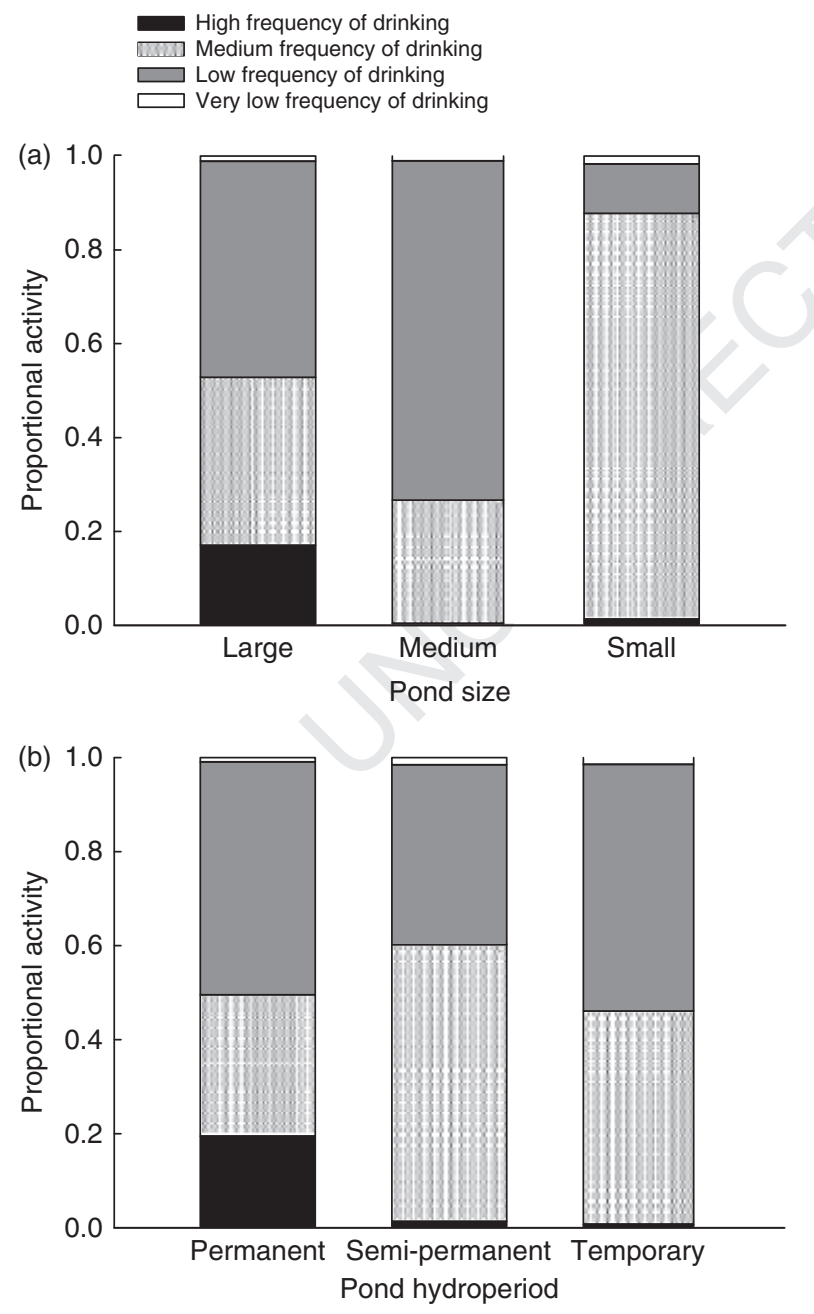

Figure 4 The proportional activity of bat species with different frequencies of drinking during the spring of 2007 over different pond size (a) and hydroperiod (b) categories.
Species with a very low frequency of drinking were not associated with either pond size or pond hydroperiod categories.

\section{Discussion}

Although at the regional scale, geographical and historical processes set the upper limit on species diversity, the localscale distribution of species within habitat patches can be determined by local environmental factors and biotic interactions (Ricklefs, 1987; Gaston, 2000; Ford et al., 2005). Therefore, species diversity is linked not only to landscape diversity (Nichols, Killingbeck \&Augus, 1998) but also to spatial and temporal diversity of local landscape components. Our study shows that spatial heterogeneity, in terms of availability of different pond size and hydroperiod categories, and temporal heterogeneity, whereby the availability and size of temporary ponds change throughout the year, are important for the maintenance of bat community diversity in the desert landscape.

Arid environments are water limited and typified by highly variable pulses of precipitation that control basic ecosystem processes (Noy-Meir, 1973). In these systems, the distribution, abundance and persistence of many mammalian species is affected by local water availability, particularly during dry and hot periods (Krausman, Rosenstock \& Cain, 2006). The majority of bat species found in the study area use natural bodies of water for either drinking or foraging. Yet, species differed in terms of their frequency of drinking and levels of activity over ponds.

The most common species, P. kuhlii and T. teniotis, are non-desert species (Yom-Tov \& Kadmon, 1998), whose abundance in the Negev Desert is thought to have increased in the past century following human settlement. Both had the highest frequencies of drinking. However, while P. kuhlii uses ponds both for drinking and foraging, $T$. teniotis forages in open spaces high above ground level (Korine \& Pinshow, 2004) and uses ponds solely for drinking.

\section{Pond size and the effect of drinking frequency and manoeuvrability}

The size of pend $_{\Omega}$ affects the local diversity and community composition of bats in both desert (Rabe \& Rosenstock, 2005) and temperate ecosystems (Francl, 2008). However, the general effect of pond size on biodiversity may differ between taxa (Oertli et al., 2002). Bats in the present study responded similarly to the experimental manipulation of pond size and the natural reduction in pond size following pond desiccation. This suggests that the observed reduction was a response to the experimental manipulation, rather than the result of the disturbance caused by the manipulation.

Species whose activity was reduced by the greatest extent following the experimental manipulation of pond size had low frequencies of drinking and tended to use ponds primarily for foraging. This reduction may be related to changes in the abundance of their prey due to the covering 
of part of the pond. Covering a section of a stream with an insect-proof cover reduces the abundance of emergent aquatic insects, and consequently reduces the activity of insectivorous bats that forage over water (Fukui et al., 2006). In contrast, the activity of high-frequency drinkers in our study was reduced by smallest extent, perhaps due to repeated attempts made by T. teniotis, a large bat with a fast, low manoeuvrability flight (Norberg \& Rayner, 1987), to drink from a pond of smaller size.

Pond length affected bat species richness, while pond volume affected bat activity levels. Measures of pond accessibility (per cent of vegetation cover) and isolation (distance to nearest permanent pond), on the other hand, did not affect bat species richness or activity. Longer ponds, regardless of their hydroperiod, accommodated bats of all frequencies of drinking, foraging modes and levels of manoeuvrability. This is because longer ponds not only provide a sufficient drinking space for less manoeuvrable species (Tuttle et al., 2006) but probably also provide more opportunities for the spatial partitioning of the pond surface. Bat captures over desert water sources in the Arizona Desert, US, confirm the increase in bat species richness over water troughs longer than $3-5 \mathrm{~m}$, with an additional increase at lengths $>15 \mathrm{~m}$ (reviewed in Taylor \& Tuttle, 2007).

Because of biases associated with the detection of bat species that emit low-intensity echolocation calls (O'Farrell \& Gannon, 1999), the activity of the two 'whispering' bats recorded in the study area, Otonycteris hemprichii and Plecotus christii, may be greater than estimated based on acoustic monitoring. Nevertheless, larger ponds had greater species richness.

Pond volume reflects the effect of pond length and depth, both of which determine the viability of the pond as a drinking site and the rate of pond desiccation. The increase of bat activity with pond volume is the consequence of the higher activity levels of three common species over larger volume ponds and their near-avoidance of small volume ponds. The activity of T. teniotis is restricted to large volume ponds due to low manoeuvrability flight (Norberg \& Rayner, 1987). The activity of $H$. bodenheimeri and $P$. rueppelli also concentrates over ponds of greater volume. Because these species commonly forage for Diptera over water (Feldman, Whitaker \& Yom-Tov, 2000), higher bat activity levels over ponds of greater volume may be related to the increase in the abundance of Diptera with pond size (Bazzanti, Grezzi \& Della Bella, 2008). Species-pond size associations indicate that although larger ponds had higher levels of bat species richness and activity, small ponds were still used by both $P$. kuhlii and bats with a very low frequency of drinking, like the two rhinolophid bats.

\section{Pond hydroperiod: the role of temporary ponds}

Pond size, and in particular pond volume, is a major determinant of pond hydroperiod, and therefore an increase in community richness with pond hydroperiod may be an artefact of the increase in richness with pond size (Brooks,
2000). In our study, there was a strong interdependence between pond hydroperiod and size (all permanent ponds had a large volume). However, although larger volume ponds may take longer to dry out, the presence of a perennial spring, rather than pond volume, is the main factor determining whether a pond is permanent in high evapotranspiration desert ecosystems (Noy-Meir, 1973).

Unlike pond size, pond hydroperiod did not affect either bat species richness or activity, suggesting that temporary ponds, when present, are as important for bat diversity as permanent ponds. Similarly, in arid central Australia, temporary water sources were found to support high bat diversity and a higher mean bat activity than permanent waters (Williams \& Dickman, 2004). This suggests that the spatio-temporal diversity provided by the temporary ponds may in itself be an important contributor to biodiversity. The importance of temporary ponds is enhanced in arid environments due to water scarcity and the concentration of vegetation around water sources (Hillel \& Tadmor, 1962), which increases the importance of all available water sources, regardless of their hydroperiod.

Pond hydroperiod did, however, affect the bat community composition as non-desert species that have a higher frequency of drinking were associated with more permanent ponds. Water quality affects bat activity over bodies of water (Racey et al., 1988); therefore, it is an area of research that should be addressed in the future.

The desiccation of temporary ponds was associated with increased species richness and activity over semi-permanent and permanent ponds due to the addition of bat species with a low frequency of drinking that were associated previously with temporary ponds, coupled with an increase in the activity of $P$. kuhlii over permanent ponds. Yet, not all of the temporary pond community shifted to more permanent ponds. P. rueppelli left the study area once temporary ponds dried out, while the activity of $H$. bodenheimeri, one of the most common bat species in the spring, declined to a minimum.

\section{Conclusions and conservation implications}

Our study highlights the importance of the diversity of local landscape components. To conserve desert bat diversity, one must strive to maintain a diversity of ponds, including ponds of different lengths, volumes and hydroperiods, as these will be utilized differently by species with different physiological and morphological characteristics. Conservation efforts in arid environments should focus on larger temporary ponds (over $15 \mathrm{~m}$ in length and $0.5 \mathrm{~m}$ in depth) because they support similar bat species richness and activity levels as permanent ponds but are less likely to be protected due to their ephemeral nature. The high activity density of nondesert species in natural habitats surrounding human settlements further stresses the importance of conserving habitat features, like temporary ponds, that are uniquely associated with the desert fauna.

Conclusions drawn from this study can be relevant for better understanding the responses of biodiversity to future 
conservation threats. Global climate change can exacerbate human-induced trends of desertification and land degradation in Mediterranean and semi-arid ecosystems (Lavee, Imeson \& Sarah, 1998). Climate change may primarily reduce the size and availability of temporary ponds, which depend on annual flooding events, and therefore are affected considerably by changes in the amount of annual precipitation. The relationship between pond size and bat diversity suggests that a reduction in the size of temporary ponds can affect both bat species richness and activity levels over ponds. Moreover, a reduction in the availability of temporary ponds is likely to affect desert bat species, and in particular species that forage over water, as they are associated with temporary ponds. These effects could be worsened by increased competition for the foraging space above ponds due to a reduced scope for spatial partitioning.

\section{Acknowledgements}

We are grateful to the Israel Nature and National Parks Protection Authority for allowing us to carry out research in the nature reserve. We wish to thank Ishai Hoffmann, Adam Fisher, Tamir Caras, Shai Philosoph and countless volunteers for their help with fieldwork. We also thank K. Safi and two anonymous reviewers for their comments on this paper. This research was funded through grants from BGU Seed Money and the Israeli Ministry of Science and Biotechnology. This is publication no. XXX of the MDDE.

\section{References}

Aldridge, H.D.J.N. \& Rautenbach, I.L. (1987). Morphology, echolocation and resource partitioning in insectivorous bats. J. Anim. Ecol. 56, 763-778.

Bazzanti, M., Grezzi, F. \& Della Bella, V. (2008). Chironomids (Diptera) of temporary and permanent ponds in Central Italy: a neglected invertebrate group in pond ecology and conservation. J. Freshw. Ecol. 23, 219-229.

Benda, P., Dietz, C., Andreas, M., Hotovy, J., Lucan, R.K., Maltby, A., Meakin, K., Truscott, J. \& Vallo, P. (2008). Bats (Mammalia: Chiroptera) of the Eastern Mediterranean and Middle East. Part 6. Bats of Sinai (Egypt) with some taxonomic, ecologic and echolocation data on this fauna. Acta. Soc. Zool. Bohem. 72, 1-103.

Biscardi, S., Russo, D., Casciani, V., Cesarini, D., Mei, M. \& Biotani, L. (2007). Foraging requirements of the endangered long-fingered bat: the influence of micro-habitat structure, water quality and prey type. J. Zool. (Lond.) 237, 372-381.

Brooks, R.T. (2000). Annual and seasonal variations and the effects of hydroperiod on benthic macroinvertebrates of seasonal forest ("vernal") ponds in Central Massachusetts, USA. Wetlands 20, 707-715.

Carpenter, R.E. (1969). Structure and function of the kidney and the water balance of desert bats. Physiol. Zool. 42, 288-302.
Collins, J. \& Jones, G. (2009). Differences in bat activity in relation to bat detector height: implications for bat surveys at proposed windfarm sites. Acta Chirop. 11, 343-350.

Feldman, R., Whitaker, J.O. \& Yom-Tov, Y. (2000). Dietary composition and habitat use in a desert insectivorous bat community in Israel. Acta. Chirop. 2, 15-22.

Fenton, M.B. (1970). A technique for monitoring bat activity with results obtained from different environments in Southern Ontario. Can. J. Zool. 48, 847-851.

Ford, W.M., Menzel, M.A., Rodrigue, J.L., Menzel, J.M. \& Jonson, J.B. (2005). Relating bat species presence to simple habitat measures in a central Appalachian forest. Biol. Conserv. 126, 528-539.

Francl, K.E. (2008). Summer bat activity at woodland seasonal pools in the northern Great Lakes region. Wetlands $\mathbf{2 8}$, $117-124$

Fukui, D., Murakami, M., Nakano, S. \& Aoi, T. (2006). Effect of emergent aquatic insects on bat foraging in a riparian forest. J. Anim. Ecol. 75, 1252-1258.

Gaston, K.J. (2000). Global patterns in biodiversity. Nature 405, 220-227.

Hillel, D. \& Tadmor, N. (1962). Water regime and vegetation in the Central Negev Highlands of Israel. Ecology 43, $33-41$.

Korine, C. \& Pinshow, B. (2004). Guild structure, foraging space use, and distribution in a community of insectivorous bats in the Negev Desert. J. Zool. (Lond.) 262, 187-196.

Krausman, P.R., Rosenstock, S.S. \& Cain, J.W. (2006). Developed waters for wildlife: science, perceptions, values, and controversy. Wildl. Soc. Bull. 34, 563-569.

Kurta, A. (2001). Bats on the surface: the need for shelter, food, and water. In Proceedings, bat conservation and mining: a technical interactive forum: 197-204. Vories, K.C. $\&$ Throgmorton, D. (Eds). St Louis.

Lavee, H., Imeson, A.C. \& Sarah, P. (1998). The impact of climate change on geomorphology and desertification along a Mediterranean-arid transect. Land. Degrad. Dev. 9, 407-422.

Marom, S., Korine, C., Wojciechowski, M.S., Tracy, C.R. \& Pinshow, B. (2006). Energy metabolism and evaporative water loss in the European free-tailed bat and Hemprich's long-eared bat (Microchiroptera): species sympatric in the Negev Desert. Physiol. Bioch. Zool. 79, 944-956.

McCain, C.M. (2007). Could temperature and water availability drive elevational species richness patterns? A global case study for bats. Glob. Ecol. Biogeogr. 16, $1-13$.

Meester, L., Declerck, S., Stoks, R., Louette, G., Van de Meutter, F., de Bie, T., Michels, E. \& Brendonck, L. (2005). Ponds and pools as model systems in conservation biology, ecology and evolutionary biology. Aquat. Conserv. 15, 715-725.

Meteorology Unit, Jacob Blaustein Institutes for Desert Research. Available at http://www.bgu.ac.il/BIDR/research/phys/meteorology/ (accessed November 2008). 
Nichols, W.F., Killingbeck, K.T. \& August, P.V. (1998). The influence of geomorphological heterogeneity on biodiversity: II a landscape perspective. Conserv. Biol. 12, 371-379.

Nicolet, P., Biggs, J., Fox, G., Hodson, M.J., Reynolds, C., Whitfield, M. \& Williams, P. (2004). The wetland plant and macroinvertebrate assemblages of temporary ponds in England and Wales. Biol. Conserv. 120, 261-278.

Norberg, U.M. \& Rayner, J.M.V. (1987). Ecological morphology and flight in bats (Mammalia; Chiroptera): wing adaptations, flight performance, foraging strategy and echolocation. Phil. Trans. Roy. Soc. Lond. Ser. B. 316, 335-427.

Noy-Meir, I. (1973). Desert ecosystems: environments and producers. Ann. Rev. Ecol. Syst. 4, 25-51.

Oertli, B., Joye, D.A., Castella, E., Juge, R., Cambin, D. \& Lachavanne, J.B. (2002). Does size matter? The relationship between pond area and biodiversity. Biol. Conserv. 104, 59-70.

O'Farrell, M.J. \& Gannon, W.L. (1999). A comparison of acoustic versus capture techniques for the inventory of bats. J. Mammal. 80, 24-30.

Rabe, M.J. \& Rosenstock, S.S. (2005). Influence of water size and type on bat captures in the Lower Sonoran Desert. West. N. Am. Nat. 65, 87-90.

Racey, P.R., Swift, S.M., Rydell, J. \& Brodie, L. (1988). Bats and insects over two Scottish rivers with contrasting nitrate status. Anim. Conserv. 1, 195-202.
Rebelo, H. \& Carlos Brito, J. (2006). Bat guild structure and habitat use in the Sahara Desert. Afr. J. Ecol. 45, 228-230.

Ricklefs, R.E. (1987). Community diversity: relative roles of local and regional processes. Science 235, 167-171.

Schneider, D.W. (1997). Predation and food web structure along a habitat duration gradient. Oecologia 110, 567-575.

Schwartz, S.S. \& Jenkins, D.G. (2000). Temporary aquatic habitats: constraints and opportunities. Aquat. Ecol. 34, 3-8.

Taylor, D.A.R. \& Tuttle, M.D. (2007). Water for wildlife: a handbook for ranchers and range managers. Bat Conservation International.

Tuttle, S.R., Chambers, C.L. \& Theimer, T.C. (2006). Potential effects of livestock water-troughs modifications on bats in Northern Arizona. Wildl. Soc. Bull. 34, 602-608.

Webb, P.I., Speakman, J.R. \& Racey, P.A. (1995). Evaporative water loss in two sympatric species of vespertilionid bat, Plecotus auritus and Myotis daubentoni: relation to foraging mode and implications for roost site selection. $J$. Zool. (Lond.) 235, 269-278.

Williams, A.J. \& Dickman, C.R. (2004). The ecology of insectivorous bats in the Simpson Desert, central Australia: habitat use. Aust. Mammal. 26, 205-214.

Yom-Tov, Y. \& Kadmon, R. (1998). Analysis of the distribution of insectivorous bats in Israel. Divers. Distrib. $\mathbf{4}$, 63-70. 


\section{Author Query Form}

\section{Journal ACV \\ Article $\quad 371$}

Dear Author,

During the copy-editing of your paper, the following queries arose. Please respond to these by marking up your proofs with the necessary changes/additions. Please write your answers clearly on the query sheet if there is insufficient space on the page proofs. If returning the proof by fax do not write too close to the paper's edge. Please remember that illegible mark-ups may delay publication.

\begin{tabular}{|c|c|c|}
\hline Query No. & Description & Author Response \\
\hline & Author: Please provide the address information for Titley Electronics: town and state. & \\
\hline Q2 & country. & \\
\hline Q3 & $\begin{array}{l}\text { Author: Please provide the manufacturer information for SONY DCR-PC110E Digital Handycam: company name, } \\
\text { town }\end{array}$ & \\
\hline Q4 & $\begin{array}{l}\text { Author: Please provide the address information for LED Model IR-8010: company name, town, state (if applicable) } \\
\text { and country. }\end{array}$ & \\
\hline Q5 & Author: Please provide the address informatin for StatSoft Inc.: town, state (if applicable) and country. & \\
\hline Q6 & Author: "This finding is ... 0.001)". The sentence has been reworded for clarity. Please check. & \\
\hline Q7 & Author: “The activity ...”. The sentence has been reworded for clarity. Please check. & \\
\hline Q8 & Author: Please provide the publication number of the MDDE. & \\
\hline Q9 & Author: Please provide the publisher for reference Kurta (2001). & \\
\hline Q10 & $\begin{array}{l}\text { Author: Please provide the title and accessed date for reference Meteorology Unit, Jacob Blaustein Institutes for } \\
\text { Desert Research. }\end{array}$ & \\
\hline Q11 & Author: Please provide the location for reference Taylor and Tuttle (2007). & \\
\hline & & \\
\hline & & \\
\hline & & \\
\hline & & \\
\hline & & \\
\hline
\end{tabular}

